\title{
Comparative Evaluation of the Fracture Resistance of Two Different Fiber-reinforced Composite Restorations with Particulate Filler Composite Restorations
}

\author{
${ }^{1}$ Arun K Patnana, ${ }^{2}$ Vanga V Narasimha Rao, ${ }^{3}$ Srinivas K Chandrabhatla, ${ }^{4}$ Vabbala R Rajasekhar
}

\begin{abstract}
Uncomplicated crown fractures are the most common form of traumatic dental injuries (TDIs) in children affecting their personal and social well-being.
\end{abstract}

\begin{abstract}
Aim: To evaluate the fracture resistance of fractured incisors restored with particulate filler composites, glass fiberreinforced composites, and Polyethylene fiber-reinforced composite restorations.
\end{abstract}

\begin{abstract}
Materials and methods: Standardized incisal and mesioincisal fractures with chamfer preparation were prepared on human maxillary central incisors. Test samples were restored using particulate filler composites (Filtek Z 250), glass fiber-reinforced composites (Fiber-Splint) and polyethylenereinforced composites (Ribbond). Static load was applied to the test samples using Universal testing machine at a crosshead speed of $1 \mathrm{~mm} / \mathrm{min}$. Data were tabulated and analyzed using analysis of variance (ANOVA) $(p=0.05)$.
\end{abstract}

Results: Descriptive statistics of mean [standard deviation (SD)] peak failure load in incisal restorations for particular filler composite, glass fiber-reinforced composites, and polyethylene fiber-reinforced composites were $196.00( \pm 67.46)$, $186.28( \pm 66.44)$, and 246.71 ( \pm 24.52$)$ respectively, whereas for mesio-incisal restorations, mean (SD) peak failure loads were $169.28( \pm 33.53), 218.57( \pm 74.41)$, and $225.71( \pm 57.52)$ respectively.

Conclusion: Polyethylene-reinforced composites showed an improved load-bearing capacity in incisal and mesio-incisal restorations when compared with particulate filler composites and glass fiber-reinforced composites.

Keywords: Fracture resistance, Glass fiber-reinforced composites, Incisal fractures, Mesio-incisal fractures, Polyethylene fiber-reinforced composites.

\footnotetext{
${ }^{1}$ Resident Doctor, ${ }^{2-4}$ Professor

${ }^{1}$ Department of Dentistry, All India Institute of Medical Sciences Jodhpur, Rajasthan, India

${ }^{2-4}$ Department of Pedodontics and Preventive Dentistry, GITAM Dental College \& Hospital, Visakhapatnam, Andhra Pradesh India

Corresponding Author: Arun K Patnana, Resident Doctor Department of Dentistry, All India Institute of Medical Sciences Jodhpur, Rajasthan, India, Phone: +919966117228, e-mail: arun0550@gmail.com
}

How to cite this article: Patnana AK, Rao VVN, Chandrabhatla SK, Rajasekhar VR. Comparative Evaluation of the Fracture Resistance of Two Different Fiber-reinforced Composite Restorations with Particulate Filler Composite Restorations. Int J Clin Pediatr Dent 2018;11(4):277-282.

\section{Source of support: Nil}

Conflict of interest: None

\section{INTRODUCTION}

Anterior crown fractures are a common form of TDIs in children and adolescents. ${ }^{1}$ It is also hypothesized that the incidence of TDI in the future might exceed the incidence of dental caries and periodontal diseases. ${ }^{2}$ The most common TDI among these are the uncomplicated crown fractures, which represent up to $51 \%$ of all TDI. ${ }^{1}$ The TDI involving the anterior teeth not only may lead to compromised tooth functioning, speech, and facial esthetics, but may also have an impact on a personality of the child and quality of life. ${ }^{3}$ Hence, immediate treatment of such a condition is required.

The treatment of an uncomplicated coronal fracture is an important challenge for the dentist because many parameters are involved in the successful outcome of the restoration. Over the years, a large number of techniques have been employed for restoration of uncomplicated crown fractures which include stainless steel crowns, orthodontic bands, resin held by pins, ${ }^{4}$ and porcelain crowns. ${ }^{5}$ However, the compromised esthetic outcomes and substantial sacrifice of the tooth structure limit their use in anterior restorations. ${ }^{6}$ Reattachment of the fractured segment is proposed to be a valid alternative for anterior restorations. Though this technique is esthetically acceptable, debonding or refracture of restored segment to the new trauma is the main drawback. ${ }^{78}$

In order to withstand the impact forces during retrauma conditions, the ideal restorative material should have high fracture resistance values. ${ }^{1}$ In the past, attempts have been made to improve the load-bearing capacity of restoration by using different bonding systems and adhesive resins. 5 These techniques have reported fracture resistance of 50 to $60 \%$ when compared with intact incisors. ${ }^{5}$

In the quest to improve the fracture resistance of the incisal restorations, different types of fibers, such as 
carbon fibers, Kevlar fibers, Vectran fibers, glass fibers, and polyethylene fibers were incorporated into the resin matrix of composites, which in turn increase the physical and mechanical properties of the restoration. Polyethylene and glass fibers improve the impact strength, modulus of elasticity, and flexural strength of composite materials. Unlike carbon and Kevlar fibers, polyethylene and glass fibers are almost invisible in resinous matrix and for these reasons, polyethylene and glass fibers seem to be the most appropriate and esthetic strengtheners of composite materials in anterior restorations. ${ }^{9}$ However, there is limited literature testing the superiority and strength of the two materials.

Hence, the objective was to assess the static load-bearing capacity of fractured incisal and mesio-incisal edges restored with conventional particulate filler composites, glass fiber-reinforced composites, and polyethylene fiberreinforced composites.

\section{MATERIALS AND METHODS}

The study was carried out in the Department of Pedodontics and Preventive Dentistry, GITAM Dental College \& Hospital, Visakhapatnam, India. Human noncarious permanent maxillary central incisors extracted for periodontal problems were collected. Teeth with any fracture or craze lines, teeth with incomplete root formation, and teeth with attrition involving incisal edge were excluded from the study. The surface debridement of teeth was done with hand scalers to remove soft tissues and calculus. The test samples were randomly divided into two groups as shown in Table 1.

Before sample preparations, custom-made strip crown preparation was done for all the samples to achieve original tooth morphology after restoration..$^{10}$ In both the groups, standardized incisal and mesio-incisal fractures were created using diamond disk under water cooling (Figs 1 and 2). A circumferential chamfer was prepared around the sectioned tooth extending $2 \mathrm{~mm}$ below the fracture line. In both the groups, the test samples were further subdivided into three subgroups based on the restorative material used as shown in Table 2.

\section{Restoration with Particulate Filler Composites}

Following incisal and mesio-incisal preparations, acid etching (Meta Etchant, Meta Biomed Co. Ltd.) was done

Table 1: Distribution of test samples

\begin{tabular}{ll}
\hline Group & Fracture pattern \\
\hline I & $\begin{array}{l}\text { Teeth subjected to crown fracture involving incisal } \\
\text { edge }\end{array}$ \\
II & $\begin{array}{l}\text { Teeth subjected to crown fracture involving mesio- } \\
\text { incisal edge }\end{array}$ \\
\hline
\end{tabular}
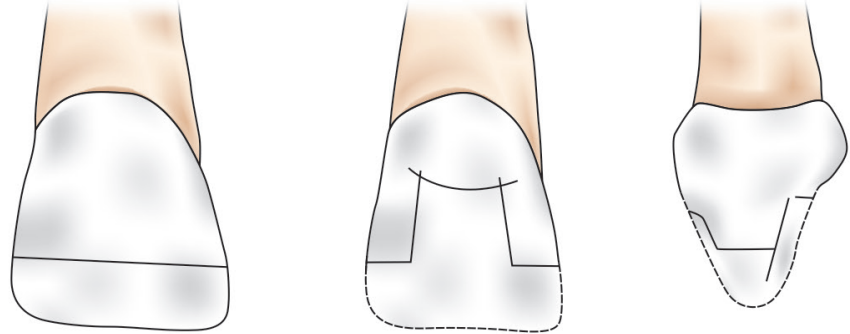

Fig. 1: Restorative procedure in incisal fracture group
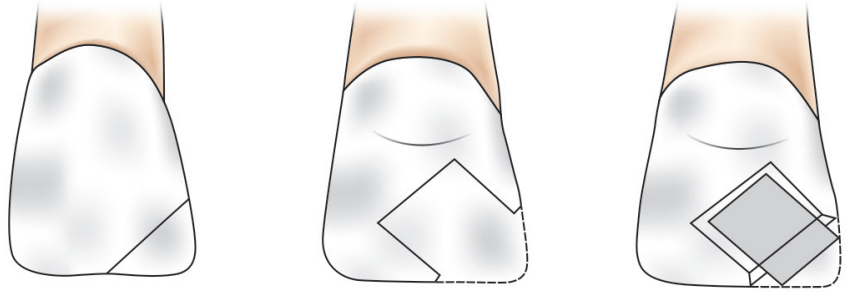

Fig. 2: Restorative procedure in mesio-incisal fracture group

Table 2: Distribution of test samples in incisal and mesio-incisal restoration groups

\begin{tabular}{llll}
\hline & Subgroup A & Subgroup B & Subgroup C \\
\hline Incisal restorations & Particulate & Glass fiber- & Polyethylene \\
(group I) and & filler & reinforced & fiber-reinforced \\
mesio-incisal & composite & composite & composite \\
restorations & restorations & restorations & restorations \\
(group II) & & & \\
\hline
\end{tabular}

and bonding agent (3M Single bond 2) was applied and light cured according to the manufacturer's instructions. Particulate filler composite (Filtek Z 250 XT, 3M ESPE) was built up and polymerized using handheld lightcuring unit. Normal tooth anatomy was restored using custom-made templates for each tooth.

\section{Restoration with Fiber-reinforced Composites}

Following the incisal and mesio-incisal preparations, additional cavity preparation $(0.5 \mathrm{~mm}$ depth, $4 \mathrm{~mm}$ mesiodistal width, and $4 \mathrm{~mm}$ cervico-incisal height) on the palatal surface of each tooth was done using a diamond bur under water coolant. Following etching, the bonding agent was applied over the fractured tooth surface and in palatal cavity. Required length of the glass and polyethylene fibers (Fiber-Splint, Polydentia SA, Switzerland; Ribbond, Ribbond INC, Seattle, Washington, USA) was measured such that the fiber bundle extended $2 \mathrm{~mm}$ below the fracture line.

The fiber was saturated with the bonding agent and excess of the bonding agent was cleared using a gentle air blow. A thin layer of a nanohybrid restorative material (Filtek Z 250, 3M ESPE, St Paul, Minnesota, USA) was carried in the palatal cavity; this thin layer of composite 

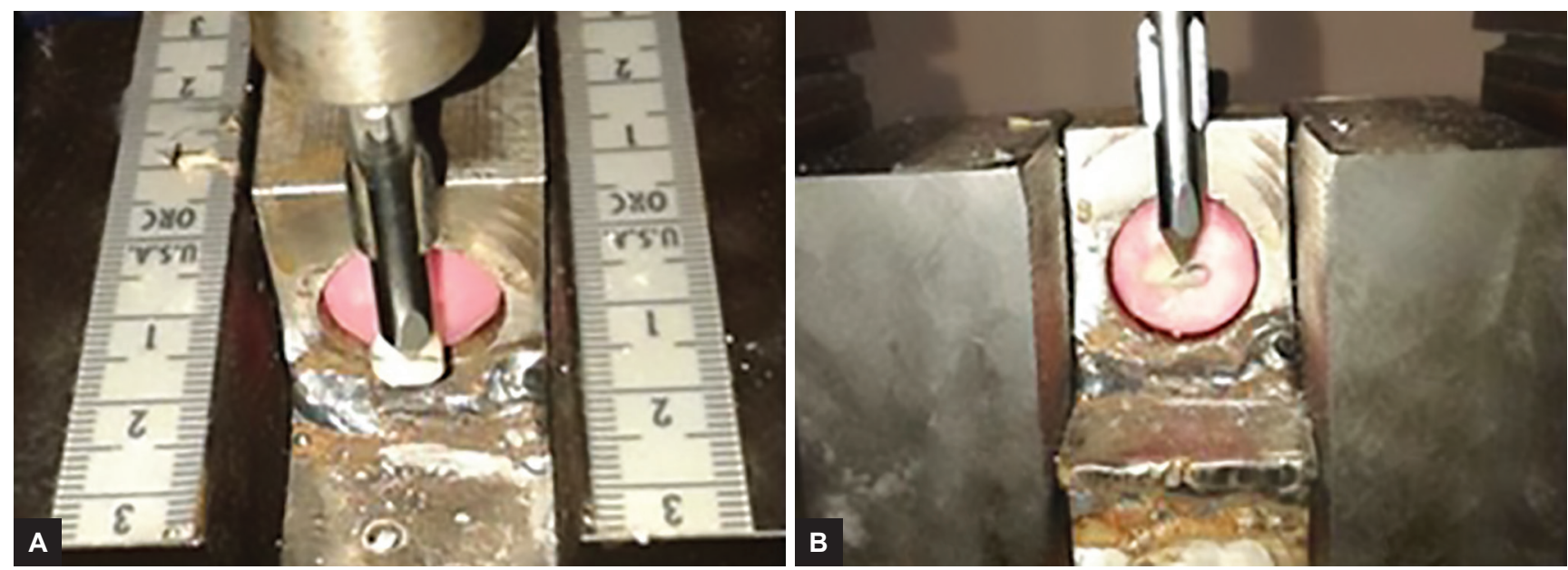

Figs 3A and B: Fracture load application in incisal and mesio-incisal test samples

acts as glue and will hold the ribbon during its adaptation. Now, the fiber bundle was placed over composite layer in the palatal cavity such that the fiber extended $2 \mathrm{~mm}$ beyond the fracture line and polymerized. Normal tooth anatomy was restored with particulate filler composites using the custom-made templates for each specimen.

After completing the restoration in all the groups, samples were stored in distilled water at room temperature for 24 hours before testing. The test samples were mounted in acrylic blocks up to cementoenamel junction using autopolymerized acrylic resin with long axis perpendicular to the base of the block. The acrylic block containing the restored tooth was tightly fixed to the custom-made inclined metal base to provide a $90^{\circ}$ angle to the horizontal plane (Fig. 3), which was held on the Universal testing machine (capacity $250 \mathrm{KN}$ and Instron make).

Compressive fatigue load was applied with a loading tip of $1 \mathrm{~mm}$ cross-head diameter, at a speed of $1 \mathrm{~mm}$ per minute, between the junction of tooth and restoration interface from labial surface with a relative angle of $90^{\circ}$ until fracture occurred. ${ }^{11}$ During the testing procedure, a reading of applied load was observed both graphically and numerically. Sudden drop in the load value of graph was considered as peak fracture load in Newton for the particular specimen.

\section{Statistical Analysis}

The data were statistically analyzed using the Statistical Package for the Social Sciences version 20 software. Descriptive statistics were done to calculate the mean, mean difference, SD. Kruskal-Wallis rank test was used to evaluate the significant difference among the three subgroups of each experimental group. When the p-value was less than 0.05 , the results were considered statistically significant.

\section{RESULTS}

The mean fracture resistance and SD of incisal and mesioincisal restoration groups are shown in Tables 3 and 4. The mean fracture loads in incisal and mesio-incisal restoration groups were presented in Graphs 1 and 2 respectively. Data from incisal restorations revealed that highest fracture resistance values were seen in polyethylene

Table 3: Intercomparison of mean peak failure loads for incisal restorations (group I)

\begin{tabular}{lllllll}
\hline Groups & $\begin{array}{l}\text { Minimum } \\
\text { load value }\end{array}$ & $\begin{array}{l}\text { Maximum } \\
\text { load value }\end{array}$ & Mean $\pm S D$ & $\begin{array}{l}\text { Mean rank } \\
\text { values }\end{array}$ & $\begin{array}{l}\text { Chi square } \\
\text { values }\end{array}$ & $p$-value \\
\hline Particulate filler composite & 53.00 & 263.00 & $196.00 \pm 67.46$ & 9.07 & 4.528 & 0.104 \\
Glass fiber-reinforced composite & 103.00 & 273.00 & $186.28 \pm 66.43$ & 8.86 & & \\
Polyethylene-reinforced composite & 205.00 & 282.00 & $246.71 \pm 24.52$ & 15.07 & & \\
\hline
\end{tabular}

Table 4: Intercomparison of mean peak failure loads for mesio-incisal restorations (group II)

\begin{tabular}{lllllll}
\hline Groups & $\begin{array}{l}\text { Minimum } \\
\text { load value }\end{array}$ & $\begin{array}{l}\text { Maximum } \\
\text { load value }\end{array}$ & Mean \pm SD & $\begin{array}{l}\text { Mean rank } \\
\text { values }\end{array}$ & $\begin{array}{l}\text { Chi square } \\
\text { values }\end{array}$ & Significance \\
\hline Particulate filler composite & 119 & 212 & $169.28 \pm 33.53$ & 6.71 & 5.039 & 0.081 \\
Glass fiber-reinforced composite & 86 & 301 & $218.57 \pm 74.41$ & 13.43 & & \\
Polyethylene-reinforced composite & 153 & 324 & $225.71 \pm 57.52$ & 12.86 & & \\
\hline
\end{tabular}




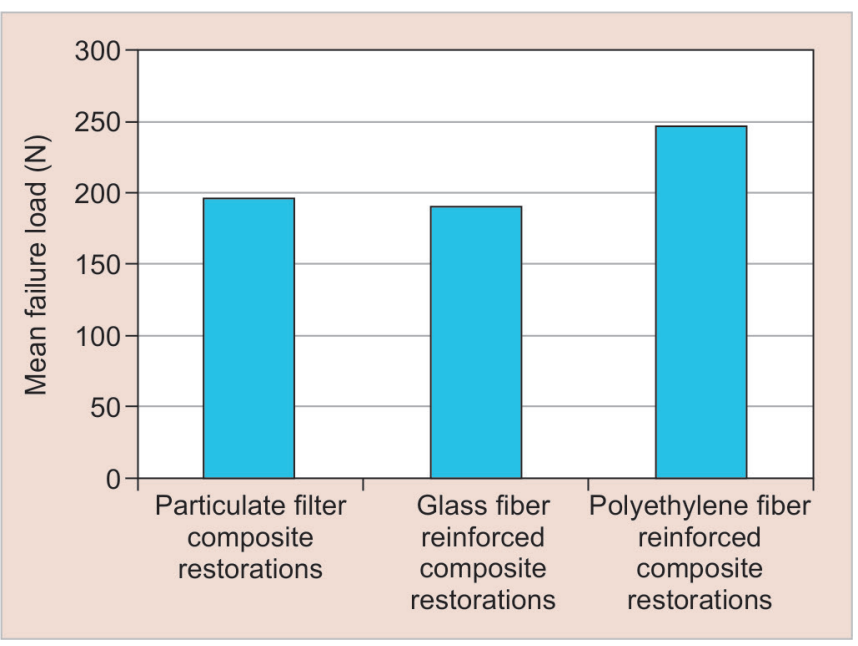

Graph 1: Mean failure loads in incisal restorations fiber-reinforced composites (246.71 \pm 24.52$)$ followed by particulate filler composites $(196.00 \pm 67.46)$ and glass fiberreinforced composites $(186.28 \pm 66.44)$. In mesio-incisal restorations, highest fracture resistance values were observed in polyethylene fiber-reinforced composites $(225.71 \pm 57.52)$ followed by glass fiber-reinforced composites (218.57 \pm 74.41) and particulate filler composite restorations (169.28 \pm 33.53). However, Kruskal-Wallis rank test showed no statistically significant difference in the mean fracture load values in the three subgroups of incisal $(p=0.104)$ and mesio-incisal $(p=0.081)$ restorations.

\section{DISCUSSION}

Extracted human maxillary central incisors were used as the test samples in the present study, as most of the prevalence studies ${ }^{12-15}$ have reported that they are involved in uncomplicated fractures resulting from direct trauma because of its position and protrusion taken during the eruptive process. ${ }^{2}$

In the present study, incisal and mesio-incisal fractures were prepared to test the fracture resistance of fiberreinforced composites, which was according to different in vitro studies ${ }^{16-19}$ for evaluating fracture toughness of composite restorations, re-attachment techniques, and different beveling techniques. Bulk pack technique using custom-made strip crowns was employed for the restorations in order to restore teeth back to their original morphology, thereby reducing the error in standardizing the amount of restorative material used. ${ }^{10}$

All teeth were sectioned at an equal distance from the incisor margin $(3 \mathrm{~mm})$ in order to obtain a standardized area of exposure. The anatomy of the surface produced by sectioning is certainly different from the surface resulting from the fracture,$^{20}$ but the choice of sectioning the teeth was dictated by the fact that sectioning establishes a repeatable condition absolutely necessary for an in vitro

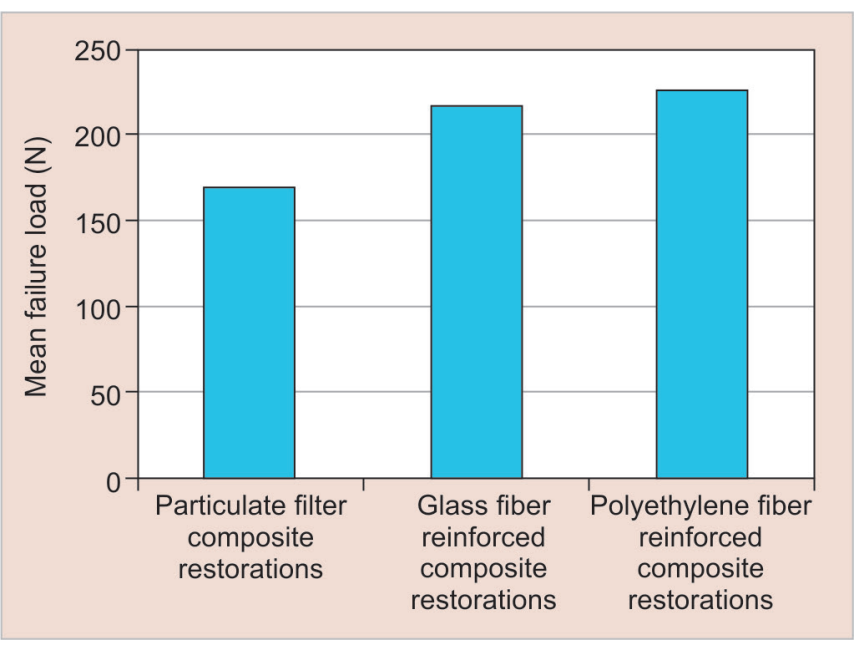

Graph 2: Mean failure loads in mesio-incisal restorations

study. A chamfer preparation of $2 \mathrm{~mm}$ below the fracture line was prepared on all the test samples in the present study as it improves the mechanical and retentive properties of composite restorations. ${ }^{16,17,21,22}$

Recently, nanocomposites showed distinct mechanical and physical properties compared with conventional resin bonded composites. ${ }^{23,24}$ Owing to its improved mechanical properties and successful clinical outcomes, nanohybrid composites were used as the control restorative material. Incorporation of fibers into the restorative materials has been suggested to increase the fracture resistance of composites. Glass and polyethylene fibers offer better esthetics, impact strength, modulus of elasticity, and flexural strength ${ }^{25-27}$; hence, they were used for reinforcing the composites in the present study.

According to Ellakwa et al, ${ }^{28}$ maximum reinforcing effect of fiber addition is gained by placement of fibers at the tensile side. However, it was also reported that placing the fibers directly on the palatal side may lead to exposure of fibers to the oral environment and may provide a plaque retention factor which in turn lead to premature failure of the restoration. ${ }^{28}$ Thus, in the present study, a thin layer of composite was placed over the fibers to prevent direct exposure to the oral environment.

Addition of fibers along with overlying composites on the palatal surfaces may result in occlusal problems. To overcome this factor, a $0.5 \mathrm{~mm}$ of tooth preparation was advised to accommodate the fibers along with overlying composites on the palatal surface. ${ }^{26}$ In accordance with different clinical case reports, ${ }^{29,30}$ a cavity of $0.5 \mathrm{~mm}$ depth on the palatal surface was prepared which extends $4 \mathrm{~mm}$ mesiodistally and $4 \mathrm{~mm}$ occluso-gingivally for all the test samples in the present study.

Successful clinical case reports were published which showed reinforcement of the composites by extending a $2 \mathrm{~mm}$ fiber material into the restoration. ${ }^{21,31}$ Thus, in the 
present study, required length of the fiber material was taken in such a way that it extended $2 \mathrm{~mm}$ beyond the fracture line to reinforce the particulate filer composite. According to different in vitro studies, ${ }^{32,33}$ loading force was applied perpendicular to long axis of the mounted specimen from labiolingual direction at a constant cross-head speed of $1 \mathrm{~mm} / \mathrm{min}$ using Universal testing machine. ${ }^{11}$

In both incisal and mesio-incisal restorations, polyethylene fiber-reinforced composites showed a maximum mean peak failure load values when compared with other experimental groups. The results of improved fracture resistance values for fiber-reinforced composites in the present study are in accordance with the clinical case reports and laboratory studies which reported that the fiber acts as individual crack-stopping units. ${ }^{34}$

According to Tezvergil et $\mathrm{al}^{35}$ and Garoushi et $\mathrm{al}^{36}$ adequate bonding between the fiber bundle and composite matrix is having critical importance. Polyethylene fibers (Ribbond) shows a semi interpenetrating polymer network (IPN) bonding between the fiber and composite resin matrix, whereas such bonding was absent in the glass fiber-reinforced composites (Fiber-Splint); thus, improved load-bearing values were observed in the polyethylene fiber-reinforced composites than glass fiber-reinforced composite restorations in the present study.

Contrary to the study results of Garoushi et al, ${ }^{37}$ particulate filler composite restorations showed higher fracture resistance values than glass fiber-reinforced composite restorations for incisal restorations in the present study; this might be because of absence of semi IPN bonding in the glass fibers (Fiber-Splint) which in turn allows the propagation of cracks between fibers and composite resin matrix and resulted in decreased load-bearing values.

However, in mesio-incisal restorations, glass fiberreinforced composites showed higher fracture load values when compared with particulate filler composites alone. These findings are in accordance with the study results of Vallittu ${ }^{38}$ where the concept of total fiber reinforcement vs partial fiber reinforcement was discussed and inferred that the reinforcing ability of the fibers will improve by increasing the area of fiber in the dentures. Similarly, in the present study, there is an increased proportion in the area of glass fibers over fractured tooth surface for mesio-incisal restorations, which resulted in improved fracture resistance values than for incisal restorations.

\section{CONCLUSION}

Analyzing the fracture resistance values in the three experimental groups, it can be concluded that polyethylene fibers (Ribbond) efficiently reinforces the incisal and mesio-incisal restorations by imparting higher stiffness to the tooth structure which in turn increases the loadbearing capacity of the tooth restoration complex.

Though every effort was taken to duplicate the oral situations in the present study, in vivo responses to the direction and impact forces might differ from the current results. The results of this in vitro investigation must be extrapolated to the clinical situation with care and further in vivo trials with these materials are indicated to confirm the validity of these recommendations.

\section{ACKNOWLEDGMENT}

The authors thankfully acknowledge Dr V Srinivas, Professor, Department of Mechanical Engineering, GITAM Institute of Technology, GITAM University, Visakhapatnam, for continuous support and guidance through the project.

\section{REFERENCES}

1. Badakar CM, Shashibhushan KK, Naik NS, Reddy VV. Fracture resistance of microhybrid composite, nano composite and fibre-reinforced composite used for incisal edge restoration. Dent Traumatol 2011 Jun;27(3):225-229.

2. Andreasen, JO.; Andreasen, FM. Textbook and color atlas of traumatic injuries to the teeth. 3rd ed. Copenhagen: Munksgaard Press; 1994.

3. Ravishankar TL, Kumar MA, Ramesh N, Chaitra TR. Prevalence of traumatic dental injuries to permanent incisors among 12 year old school children in Davangere, South India. Chin J Dent Res 2010 Jan;13(1):57-60.

4. Kahabuka FK, Plasschaert A, van't Hof M. Prevalence of teeth with untreated dental trauma among nursery and primary school pupils in Dar es Salaam, Tanzania. Dent Traumatol 2001 Jun;17(3):109-113.

5. Andreasen, JO.; Andreasen, FM.; Andreasen, L. Textbook and color atlas of traumatic injuries to the teeth. 4 th ed. Ames (IA): Blackwell Publishing Ltd; 2007.

6. McEwen JD, McHugh WD, Hitchin AD. Fractured maxillary central incisors and incisal relationship. J Dent Res 1967;46:1290-1294.

7. Andreasen FM, Noren JG, Andreasen JO, Engethardtsen S, Lindh-Stromberg U. Long-term survival of fragment bonding in the treatment of fractured crowns: a multicenter clinical study. Quintessence Int 1995 Oct;26(10):669-681.

8. Munksgaard EC, Hojtved L, Jorgensen EH, Andreasen JO, Andreasen FM. Enamel-dentin crown fractures bonded with various bonding agents. Endod Dent Traumatol 1991 Apr;7(2):73-77.

9. Uzun G, Hersek N, Tincer X. Effect of five woven fiber reinforcements on the impact and transverse strength of a denture base resin. J Prosthet Dent 1999 May;81(5):616-620.

10. Bagheri J, Denehy GE. Effect of enamel bevel and restoration lengths on class IV acid-etch retained composite resin restoration. J Am Dent Assoc 1977 Dec;95:795-803.

11. International Organization for Standardization. ISO TR 11405, Dental materials - guidance on testing of adhesion to tooth structure. Geneva: ISO; 1994. 
12. Bastone EB, Freer TJ, McNamara JR. Epidemiology of dental trauma: a review of literature. Aust Dent J 2000 Mar;45(1):2-9.

13. Gupta K, Tandon S, Prabhu D. Traumatic dental injuries to the incisors in children of South Kanara district. A prevalence study. J Indian Soc Pedod Prev Dent 2002 Sep;20(3): 107-113.

14. Nik-Hussein NN. Traumatic dental injuries to anterior teeth among school children in Malasia. Dent Traumatol 2001 Aug;17(4):149-152.

15. Petti S, Tarsitani G. Traumatic injuries to anterior teeth in Italian school children: prevalence and risk factors. Endod Dent Traumatol 1996 Dec;12(6):294-297.

16. Hani Eid H, White GE. Class IV preparations for fractured anterior teeth restored with composite resin restorations. J Clin Pediatr Dent 2003 Apr;27(3):201-211.

17. Eid H. Retention of composite resin restorations in class IV preparations. J Clin Pediatr Dent 2002 Spring;26(3):251-256.

18. Poojary PK, Bhandary S, Srinivasan R, Nasreen F, Pramod J, Mahesh M. Influence of restorative technique, bevelling and aging on composite bonding to sectioned incisal edges: a comparative in vitrostudy. J Conserv Dent 2013 Jan;16(1):28-31.

19. Tovo MF, dos Santos PR, Kramer PF, Feldens CA, Sari GT. Prevalence of crown fractures in 8-10 years old schoolchildren in Canoas, Brazil. Dent Traumatol 2004 Oct;20(5):251-254.

20. Garoushi S, Vallittu PK, Lassila LV. Short glass fiber reinforced restorative composite resin with semi-interpenetrating polymer network matrix. Dent Mater 2007 Nov;23(11):1356-1362.

21. Vitale MC, Caprioglio C, Martignone A, Marchesi U, Botticelli AR. Combined technique with polyethylene fibers and composite resins in restoration of traumatized anterior teeth. Dent Traumatol 2004 Jun;20(3):172-177.

22. MJ Davis MJ, Roth J, Levi M. Marginal integrity of adhesive fracture restorations: chamfer versus bevel. Quintessence Int 1983 Nov;14(11):1135-1146.

23. Scott A Saunders SA. Current practicality of nanotechnology in dentistry. Part 1: focus on nanocomposite restoratives and biomimetics. Clin Cosmet Investig Dent 2009 Nov;1:47-61.

24. 3M Dental Product Laboratory (US). FiltekTM Z250 Universal technical system: technical product profile. St. Paul (MN): Dental Product Laboratory; 1998. Available from: http:/ / solutions.3m.com/wps/portal/3M/en_US/3M-ESPE-NA/ dental-professionals / products / espe-catalog/ /FiltekZ250-Universal-Restorative.
25. Meng Zhang M, Matinlinna JP. E-Glass fiber reinforced composites in dental applications. Silicon 2012 Jan;4(1):73-78.

26. Sema Belli S, Eskitascioglu G. Biomechanical properties and clinical use of a polyethylene fibre post-core Material; Int Dent South Africa 2011 May-Jun;8(3):20-26.

27. Ruffino AR. Effect of stainless steel strengthener on fracture resistance of the acrylic resin complete denture base. J Prosthet Dent 1985 Jul;:54(1):75-78.

28. Ellakwa AE, Shortall AC, Shehata MK, Marquis PM. The influence of fibre placement and position on the efficiency of reinforcement of fibre reinforced composite bridgework. J Oral Rehab 2001 Aug;28(8):785-791.

29. Tuloglu N, Bayrak S, Tunc ES. Different clinical applications of bondable reinforcement ribbond in pediatric dentistry. Eur J Dent 2009 Oct;3(4):329-334.

30. Amir Chafaie A, Portier R. Anterior fiber-reinforced composite resin bridge: a case report. Pediatr Dent 2004 NovDec;26(6):530-534.

31. Praveen Kumar PS, Nandlal B, Srilatha KT. Restoration of fractured central incisor using glass fiber-reinforced composite resin (GFRCR): a case report. Indian Dent Res Rev 2009.

32. Dean JA, Avery DR, Swartz ML. Attachment of anterior tooth fragments. Pediatr Dent 1986 Jun;8(3):139-143.

33. Stellini E, Stomaci D, Stomaci M, Petrone N, Favero L. Fracture strength of tooth fragment reattachments with postpone bevel and overcontour reconstruction. Dent Traumatol 2008 Jun;24(3):283-288.

34. Petersen RC. Discontinuous fiber-reinforced composites above critical length. J Dent Res 2005 Apr;84(4):365-370.

35. Tezvergil A, Lassila LV, Yli-Urpo A, Vallittu PK. Repair bond strength of restorative resin composite applied to fiber reinforced composite substrate. Acta Odontol Scand 2004 Jul;62(1):51-60.

36. Sufyan Garoushi S, Lassila LV, Tezvergil A, Vallittu PK. Load bearing capacity of fibre-reinforced and particulate filler composite resin combination. J Dent 2006 Mar;34(3):179-184.

37. Sufyan K. Garoushi SK, Lassila LV, Vallittu PK. Direct composite resin restoration of an anterior tooth: effect of fiberreinforced composite substructure. Eur J Prosthodont Restor Dent 2007 Jun;15(2):61-66.

38. Vallittu PK. Glass fibre reinforcement in repaired acrylic resin removable dentures: preliminary results of a clinical study. Quintessence Int 1997 Jan;28(1):39-44. 